\title{
Analysis of effect of reinforcement on concrete creep behavior
}

\author{
J.D. Xin, J.H. Li \& D.H. Huang \\ Beihang University, Beijing, China
}

Keywords: Reinforced concrete; creep; reinforcement ratio

\begin{abstract}
Considerable deformation generates when concrete is with long-term loading and creep is one of the most important time-dependent behaviors and needs to be paid enough attention. It is of great important to understand the workability and liability of structures under long-term loading. This paper presents a method for calculation of concrete stress and strain considering effect of reinforcement and factor of reinforcement ratio has been considered. Results show that concrete stress can be reduced to some extent when reinforcement is placed under long-term loading and a reinforcement ratio of $3 \%$ is favorable. In addition, a reinforcement impact factor is recommended to quantify effect of reinforcement on concrete creep behavior.
\end{abstract}

\section{Introduction}

Concrete has been proved to be one of most important material for construction. Creep is one kind of time-dependent behaviors and effect of creep on concrete is complicated. On one hand, the risk of concrete crack is reduced considering concrete creep and relaxation behavior; on the other hand, part of prestress is lost during concrete creep. Coupling effect of structure dimension, restraint condition and adjoining members affects the evolution of concrete stress. Fig. 1 shows the evolution of concrete stresses of different positions and it can be seen that the evolution of concrete stress at top and bottom point of concrete wall can be opposite [1]. For practice, most of concrete structures are reinforced. The effect of reinforcement on evolution of concrete stress still need to be paid attention as a additional restraint is provided by reinforcement because of difference between steel and concrete materials.

For reinforced concrete structures under short-term loading, the usage of reinforcement is not to prevent concrete from cracking [2], but to limit the deflection and crack width of reinforced concrete members [3]. It should be noted that aforementioned conclusions about reinforcement are based on results under short-term loading, without considering time-dependent behavior of concrete. As a matter of fact, concrete structures after casting undergo changing environment and are impacted by external and internal restraints continuously [4]. Concrete creep theory has been improved and supplemented for decades [5-7] and a numerous of researchers studied the mechanical behavior of reinforced concrete [8-12].

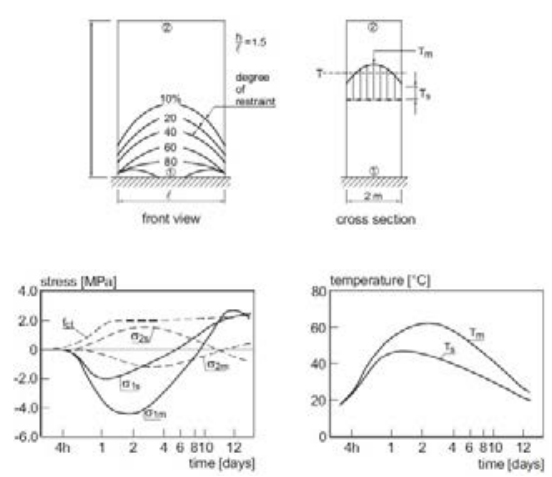

Figure 1. Evolution of concrete stress under different restraint conditions [1]

This paper presents a method for calculation of concrete creep behavior under long-term loading and effect of reinforcement on concrete stress and strain has been quantitatively assessed by introducing a reinforcement impact factor. 


\section{Methodology}

The concrete creep has been improved since the early twentieth century and numerous theories, such as effective modulus method, ageing theory and elastic creep theory [1], has been widely used for calculation of concrete creep.

The elastic creep theory assume that the relation between deformation and stress is proportional and the total creep deformation can be attributed by the summation of creep caused by corresponding stress increment, known as superposition principle

$$
\varepsilon_{\text {total }}(t)=\sigma\left(t_{0}\right)\left[\frac{1}{E\left(t_{0}\right)}+C\left(t, t_{0}\right)\right]+\int_{t_{0}}^{t}\left[\frac{1}{E(\tau)}+C(t, \tau)\right] d \sigma(\tau)
$$

where $E\left(t_{0}\right)$ is concrete elastic modulus at loading age of $t_{0}, E(\tau)$ the concrete elastic modulus at age of $\tau, C(t, \tau)$ the specific creep of concrete.

\section{Calculation of concrete creep}

1.1 Basic assumption

The perfect bond between steel and concrete is the key to insure the workability of reinforced concrete. For newly cast reinforced concrete structures, the deformation compatibility of steel and concrete should be considered firstly at early-age. Mimura et al. [13] studied the pull-out test under different concrete ages and found that the deformation of reinforcement and concrete was almost same under low loading level and the bond stress at early-age guarantees the workability of reinforced concrete. Therefore, the basic assumptions are as follows:

(1) plane cross-section assumption; (2) no slippage between reinforcement and concrete; (3) no cracking of concrete; (4) no stress-independent strain.

1.2 Creep analysis of reinforced concrete

Concrete creep generates after initial loading, and then concrete stress and strain can be calculated by circular computation of each divided time increment. The corresponding strain and stress increment can be expressed as [14]

where $f_{i}, g_{i} p_{i} \gamma_{s}$ are parameters of concrete specific creep.

$$
\begin{gathered}
\Delta \varepsilon_{n}^{e}=\int_{t_{0}}^{t} \frac{1}{E(\tau)} \frac{d \sigma}{d \tau} d \tau=\frac{\Delta \sigma_{n}}{E\left(\bar{\tau}_{n}\right)} \\
\Delta \varepsilon_{n}^{c}=\eta_{n}+\Delta \sigma_{n} C\left(t_{n}, \bar{\tau}_{n}\right) \\
\Delta \varepsilon_{n}=\Delta \varepsilon_{n}^{e}+\Delta \varepsilon_{n}^{c} \\
\Delta \sigma_{n}=\bar{E}_{n}\left(\Delta \varepsilon_{n}-\eta_{n}\right) \\
\Delta \bar{E}_{n}=\frac{E\left(\bar{\tau}_{n}\right)}{1+E\left(\bar{\tau}_{n}\right) C\left(t_{n}, \bar{\tau}_{n}\right)} \\
\eta_{n}=\sum\left(1-e^{-r_{s} \Delta t_{n}}\right) \omega_{s n} \\
\omega_{s n}=\omega_{s, n-1} e^{-\gamma_{s} \Delta t_{n-1}}+\Delta \sigma_{n-1} \psi_{s}\left(\bar{\tau}_{n-1}\right) e^{-0.5 \gamma_{s} \Delta t_{n-1}} \\
\omega_{s 1}=\Delta \sigma_{0} \psi_{s}\left(\tau_{0}\right) \\
\psi_{s}=\sum f_{i}+g_{i} \tau^{-p_{i}}
\end{gathered}
$$

As can be seen from Fig.2, the deformation of reinforced concrete is reduced because of the restraint by reinforcement and part of concrete stress can be transferred during this period. The concrete strain increment should be same with that of reinforcement because of deformation compatibility.

$$
\Delta \varepsilon_{n}^{c}=\frac{\Delta \sigma_{n}}{\bar{E}_{n}}+\eta_{n}=\Delta \varepsilon_{n}^{s}=\frac{\Delta N / A_{s}-\rho \Delta \sigma_{n}}{E_{s}}
$$


where $\Delta N$ is the increment of load, $E_{s}$ the elastic modulus of reinforcement, $A_{s}$ the area of reinforcement, $\rho$ the area ratio of concrete to reinforcement.

Equation (11) can be described by the following expression and concrete stress and strain at arbitrary age can be calculated.

$$
\Delta \sigma_{n}=\frac{E_{s} \bar{E}_{n}}{E_{s}+\rho \bar{E}_{n}}\left(\frac{\Delta N}{A_{s} E_{s}}-\eta_{n}\right)
$$

\section{Case study}

The dimensions of cross section of reinforced concrete are shown in Fig.3. The length of each side is $200 \mathrm{~mm}$, and the ratio of reinforcement is $1 \%$.

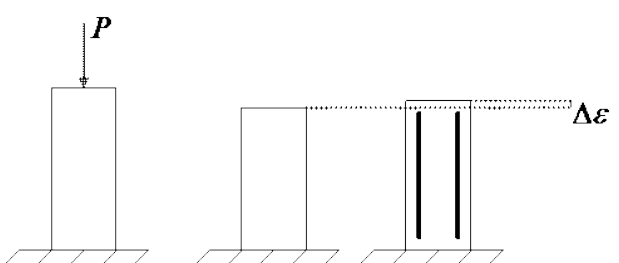

Figure 2. Deformation of plain and reinforced concrete

The elastic modulus of concrete equals $E_{c}(\tau)=33000\left(1-\exp \left(-0.4 * \tau^{0.34}\right)\right)$ [14]. The elastic modulus of steel is $2 \times 10^{5} \mathrm{MPa}$, and the initial external load is assumed to be $60 \mathrm{Kn}$. The loading age $\tau$ is 7 days and the specific creep of concrete $C(t, \tau)$ takes the following expression [13].

$$
C(t, \tau)=\sum_{j=1}^{2}\left(f_{i}+g_{i} \tau^{-p_{i}}\right)\left[1-e^{-r_{i}(t-\tau)}\right]
$$

where $\tau$ is the loading age and $t$ is the concrete age.

Creep parameters are given in table 1.

\begin{tabular}{ccccc} 
Table 1. & \multicolumn{5}{c}{ Parameters of specific creep [13] } \\
\hline Parameter & $f_{i}\left(10^{-4}\right)$ & $g_{i}\left(10^{-4}\right)$ & $p_{i}$ & $\gamma_{i}$ \\
& & & & \\
\hline $\mathrm{i}=1$ & 0.1045 & 0.9614 & 0.7 & 0.3 \\
$\mathrm{i}=2$ & 0.2360 & 0.4012 & 0.7 & 0.05 \\
\hline
\end{tabular}

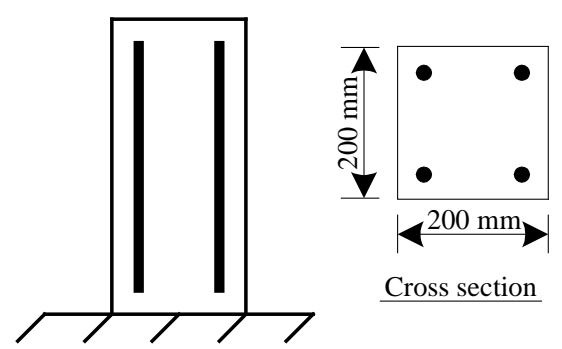

Figure 3. Dimension of reinforced concrete and reinforcement configuration

1.3 Concrete and reinforcement stress

The concrete and reinforcement stress can be calculated according to section 3.2 and the results are presented in Fig.4.

As expected, concrete stresses are gradually transferred to reinforcement as concrete creep develops. It is interesting to note that the concrete stress reduction seems rapidly at first days and then becomes flat at late-age, which is consistent with the evolution of concrete creep behavior.

Fig. 5 shows the concrete stress transfer under different reinforcement ratios. It can be seen that 
the restraint of reinforcement on concrete becomes stronger with the increasing reinforcement ratios and more concrete stress is transferred to reinforcement during this process. From the viewpoint of concrete creep, the positive effect of reinforcement on reduction of concrete stress is considerable when the reinforcement is $3 \%$.

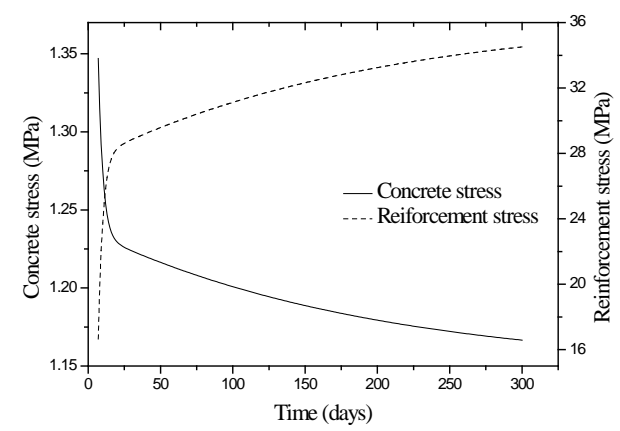

Figure 4. Evolution of stress of concrete and reinforcement ( $\tau=7 d, \rho=1 \%)$

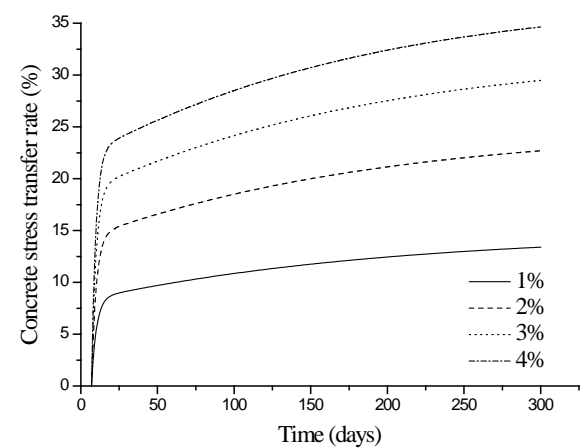

Figure 5. Concrete stress transfer rate under different reinforcement ratios

\subsection{Reinforcement impact factor}

The computer calculation of concrete strain and stress is accurate, however, it is still unclear that how parameters, such as concrete age, reinforcement ratio, affect the stress distribution during loading period. Herein, the age-adjusted effective modulus method is adopted to analyze effect of reinforcement on concrete creep.

The total strain of concrete when applied an initial stress at takes the following expression [2]

$$
\varepsilon_{\text {total }}(t)=\frac{\sigma_{0}}{E_{c}\left(t_{0}\right)}\left[1+\varphi\left(t, t_{0}\right)\right]+\frac{\sigma(t)-\sigma_{0}}{E_{c}\left(t_{0}\right)}\left[1+\chi\left(t, t_{0}\right) \varphi\left(t, t_{0}\right)\right]
$$

where $\varphi\left(t, t_{0}\right)$ is creep coefficient, $\chi\left(t, t_{0}\right)$ the ageing coefficient.

The strain increment of concrete can be expressed by Equation (15)

$$
\Delta \varepsilon\left(t, t_{0}\right)=\frac{\sigma_{0}\left(t_{0}\right)}{E_{c}\left(t_{0}\right)} \varphi\left(t, t_{0}\right)+\frac{\sigma(t)-\sigma_{0}\left(t_{0}\right)}{E_{c}\left(t_{0}\right)}\left[1+\chi\left(t, t_{0}\right) \varphi\left(t, t_{0}\right)\right]
$$

Based on deformation compatibility and force equilibrium, one can obtain

$$
\begin{gathered}
\Delta N_{s}+\Delta N_{c}=0 \\
\Delta N_{s}=\Delta \varepsilon\left(t, t_{0}\right) E_{s} A_{s}
\end{gathered}
$$

Substituting Equation (16) and (17) into (15), the strain increment of concrete can be expressed as

$$
\Delta \varepsilon_{c}\left(t, t_{0}\right)=\frac{\sigma_{0}\left(t_{0}\right)}{E_{c}\left(t_{0}\right)} \varphi\left(t, t_{0}\right) /\left\{1+\frac{E_{s} A_{s}}{E_{c}\left(t_{0}\right) A_{c}}\left[1+\chi\left(t, t_{0}\right) \varphi\left(t, t_{0}\right)\right]\right\}
$$

Equation (18) consists of factors that affect deformation evolution of concrete. $\sigma_{0}\left(t_{0}\right) /\left[\varphi\left(t, t_{0}\right) E_{c}\left(t_{0}\right)\right]$ represents the creep strain of plain concrete and a reinforcement impact factor 
$\lambda=1 /\left\{1+E_{s} A_{s}\left[1+\chi\left(t, t_{0}\right) \varphi\left(t, t_{0}\right)\right] E_{c}\left(t_{0}\right) A_{c}\right\}$, which involve in loading age, concrete age and reinforcement ratio, can be used to evaluate concrete creep behavior under long-term loading. As can be seen from Fig.6, this impact factor is less than 1.0; besides, $\lambda$ drops fast at first loading age and becomes constant afterwards.

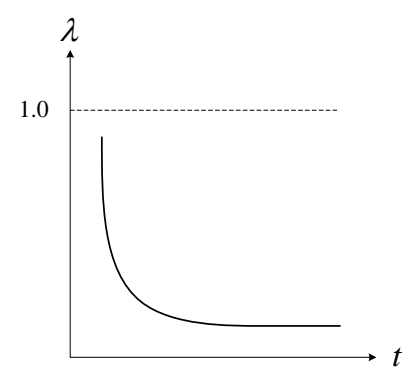

Figure 6. Evolution of $\lambda$

\section{Conclusions}

1. The concrete stress is gradually transferred to reinforcement during loading period. The concrete stress reduction rate seems rapidly at first days and then becomes flat at late-age, which is consistent with the evolution of concrete creep behavior. The positive effect of reinforcement on reduction of concrete stress is considerable when the reinforcement is $3 \%$.

2 . The reinforcement impact factor $\lambda$ combines factors, such as loading age, reinforcement ratio and stress level and can be used to evaluate concrete creep behavior under long-term loading. This impact factor is less than 1.0 and becomes constant afterwards.

\section{Acknowledgments}

This study was part of a research project supported by China Three Gorges Corporation (grant number TGC-2012746379).

\section{References}

[1] Emborg, M. \& Bernander, S. 1994. Assessment of risk of thermal cracking in hardening concrete. Journal of Structural Engineering ASCE, 120(10):2893-2912.

[2] Huang, G.X., Hui, R.Y. \& Wang, X.J. 2011. Concrete creep and shrinkage. China electric power press, Beijing, China.

[3] Koga, H., Watanabe, H., Takeuchi, Y., Aoyama, H. \& Kitano Y. 2009. Experimental study on the time dependent flexural behavior of prestressed reinforced concrete beams. Creep, Shrinkage and Durability Mechanics of Concrete and Concrete Structures - Proceedings of the 8th International Conference on Creep, Shrinkage and Durability Mechanics of Concrete and Concrete Structures, 1:781-786.

[4] Marí, A.R., Bairán, J.M. \& Duarte, N. 2010. Long-term deflections in cracked reinforced concrete flexural members. Engineering Structures, 32(3):829-842.

[5] Mimura, Y., Yoshitake, I. \& Zhang W.B. 2011. Uniaxial tension test of slender reinforced early age concrete members. Materials, 4:1345-1359.

[6] Mu, G.B., Wang, L.G. \& Wang, C. 2007. Creep effect analysis of steel reinforced concrete beam. Journal of Northeastern University (Natural Science), 28(5):733-736.

[7] Pan, Z.F., Zhang Z.T. \& Meng S.P. 2009. Experimental study on the influence of steel on highstrength concrete creep and shrinkage. China Civil Engineering Journal, 42(2):11-16. 
[8] Piyasena, R., Loo, Y.C. \& Fragomeni, S. 2003. Determination of crack spacing and crack width in reinforced concrete beams. Structural Engineering and Mechanics, 15(2):159-180.

[9] Ranaivomanana, N., Multon, S. \&Turatsinze A. 2013. Basic creep of concrete under compression, tension and bending. Construction and Building Materials, 38(1):173-180.

[10] Reinhardt, H. \& Rinder, T. 2006. Tensile creep of high-strength concrete. Journal of Advanced Concrete Technology, 4(2):277-283.

[11] Rossi, P., Tailhan, J.L., Le Maou, F., Gaillet, L. \& Martin E. 2012. Basic creep of concretes investigation of the physical mechanisms by using acoustic emission. Cement and concrete research, 42(1):61-73.

[12] Song, W., Yuan Y. \& Gong, J. 2002. Experimental research on tensile performance of reinforced concrete. Journal of southeast university (Natural Science Edition), 32 Sup.:98-101.

[13] Xue, W.C., Hu, Y.M. \& Wang, W. 2008. Experiment on creep behaviors of prestressed concrete beams. China Journal of Highway and Transport, 21(4):61-66.

[14] Zhu, B.F. 2009. Thermal stresses and temperature control of mass concrete. China Water \& Power Press, Beijing, China. 